$\mathrm{DE}$

M E D I C I N A

T R O P I C A L

$\mathrm{DE}$

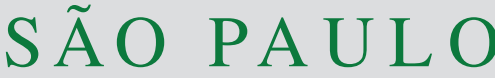

JOURNAL OF THE SÃO PAULO INSTITUTE OF TROPICAL MEDICINE

${ }^{1}$ Fundação Oswaldo Cruz, Instituto Nacional de Infectologia Evandro Chagas, Laboratório de Micologia, Setor Imunodiagnóstico, Rio de Janeiro, Rio de Janeiro, Brazil

${ }^{2}$ Hospital São José de Doenças Infecciosas, Fortaleza, Ceará, Brazil

${ }^{3}$ Universidad Nacional Autónoma de México, Facultad de Medicina, Departamento de Microbiología y Parasitología, Laboratorio de Inmunología de Hongos, Ciudad de México, México

${ }^{4}$ Universidade Federal do Ceará, Faculdade de Medicina, Departamento de Saúde Comunitária, Fortaleza, Ceará, Brazil

Correspondence to: Lisandra Serra Damasceno

Fundação Oswaldo Cruz, Instituto Nacional de Infectologia Evandro Chagas, Laboratório de Micologia, Setor Imunodiagnóstico, Av. Brasil, 4365, Manguinhos, CEP 21040-360,

Rio de Janeiro, RJ, Brazil

Tel: +55 21 3865-9557

Fax: +55 $212590-9988$

E-mail: lisainfecto@gmail.com

Received: 25 August 2018

Accepted: 20 December 2018

\section{Mixed infection by Histoplasma capsulatum isolates with different mating types in Brazilian AIDS-patients}

Lisandra Serra Damasceno ${ }^{1,2}$, Tania Vite-Garín ${ }^{3}$, José Antonio Ramírez ${ }^{3}$, Gabriela Rodríguez-Arellanes ${ }^{3}$, Marcos Abreu de Almeida', Mauro de Medeiros Muniz ${ }^{1}$, Jacó Ricarte Lima de Mesquita², Terezinha do Menino Jesus Silva Leitão ${ }^{2,4}$, Maria Lucia Taylor ${ }^{3}$, Rosely Maria Zancopé-Oliveira ${ }^{1}$

\section{ABSTRACT}

Mixed infection by Histoplasma capsulatum isolates with different mating types, in AIDS-patients are described in this study. Morphological, mating type-specific PCR assay and multilocus sequencing type analysis of $H$. capsulatum isolates recovered from two Brazilian AIDS-patients were performed. Five $H$. capsulatum isolates were recovered at different times from the two patients. Three isolates were obtained from bone marrow (day 1-CE0411) and buffy coat cultures (day 1-CE0311; day 2-CE0511) of patient 1, and two isolates were isolated from buffy coat cultures (day 3 - CE2813; day 12 - CE2513) of patient 2. The mycelial colonies depicted different textures and pigmentation features. Dimorphic conversion to the yeast-phase in ML-Gema medium was achieved in all isolates. MAT1-1 idiomorph was identified in CE0311, CE0411 and CE2813 isolates; MAT1-2 idiomorph was found in CE0511 and CE2513 isolates. These H. capsulatum isolates were grouped within LAm A clade, highlighting that CE0311 and CE0411 isolates formed a subgroup supported by a high bootstrap value. The CE0511, CE2513, and CE2813 isolates clustered together with a Brazilian H151 isolate. This research reports mixed infections caused by $H$. capsulatum isolates with different mating types in Brazilian AIDS-patients for the first time in the literature.

KEYWORDS: Mixed infection. Histoplasma capsulatum. Mating types. Multilocus sequence typing. Histoplasmosis. HIV coinfections.

\section{INTRODUCTION}

Histoplasma capsulatum is a dimorphic fungus found in the form of mold in the environment and in vitro at $25-28^{\circ} \mathrm{C}$. The yeast form is observed during parasitism conditions or in cultures at $34-37^{\circ} \mathrm{C}$ in enriched media ${ }^{1}$. Histoplasma infection can occur in individuals that are exposed to fungal micro-niches rich in bat guano or bird droppings ${ }^{1}$. Severe forms of histoplasmosis usually occur in individuals with immunosuppression, such as AIDS-patients ${ }^{2}$.

The asexual stage or anamorph $(H$. capsulatum $)$ is an eukaryotic and heterothallic microorganism found in the environment as haploid mycelium associated with + or - mating types ${ }^{3}$. Ajellomyces capsulatus is the sexual stage or teleomorph of $H$. capsulatum, resulting from the sexual compatibility + and - of $H$. capsulatum isolates ${ }^{4}$. Both fungal stages represent the same holomorph ${ }^{3-5}$.

$H$. capsulatum has a bipolar mating system that expresses transcription factors encoded at the MAT1 locus ${ }^{6,7}$. In this fungus, this locus presents two idiomorphs, MAT1-1 and MAT1-2, which define the + and - mating types, respectively ${ }^{6}$. In 
some fungi as Cryptococcus neoformans and Aspergillus fumigatus, the mating type is associated with the virulence ${ }^{8,9}$. In addition, mixed infections with different mating types have been rarely described in pathogenic fungi ${ }^{10}$.

A high genetic diversity of $H$. capsulatum has been reported worldwide ${ }^{11-13}$. In 2003, the performance of multilocus sequencing type (MLST) by partial amplification of four nuclear protein-coding genes, ADP-ribosylation factor (arf), $\mathrm{H}$ antigen precursor ( $H$-anti), delta-9 fatty acid desaturase (ole 1$)$ and alpha-tubulin $(t u b l)$ indicated the presence of eight phylogenetic clades among 149 H. capsulatum isolates from 25 countries ${ }^{11}$. The results of theses analyses revealed the presence of NAm 1 and NAm 2 clades in North America; LAm A and LAm B clades in Latin America; Africa clades restrict to Africa; Euroasian clades constituted from fungal isolates from Egypt, India, China, Thailand and England; Netherlands clades; an Australian clade ${ }^{11}$. In addition, diverse new lineages have also been identified in different geographic regions of the world ${ }^{11,12}$. A recent study performed with a broad number of fungal isolates $(n=234)$ and more robust phylogenetic analyses identified five new phylogenetic clades, with a great admixture among $H$. capsulatum isolates from Latin America $^{14}$. The LAm A clade was regrouped in LAm A1, LAm A2 and LAm B clade was reclassified in LAm B1 and LAm B2 ${ }^{14}$. In addition, two new phylogenetic clades (RJ from Southeastern Brazil and BCA1 from Mexico), and four monophyletic clusters in Brazil (BR1-4) were identified.

Here, two cases of mixed infection with different mating types of $H$. capsulatum in AIDS-patients are reported. In addition, the five $H$. capsulatum isolates obtained from these cases of histoplasmosis in AIDS-patients were evaluated by morphological criteria, mating type determination and phylogenetic classification by MLST analysis.

\section{MATERIAL AND METHODS}

\section{Medical records}

Clinical data of patients with histoplasmosis and AIDS from Sao Jose Hospital, Fortaleza city, Ceara State, Brazil, were retrospectively retrieved from medical records. Only patients that had positive cultures for H. capsulatum in two or more different samples or in different hospitalization time, between 2011 to 2014 period were included. A total of 13 biological samples of six patients were studied by mating type- PCR. Only two patients were selected because they presented more than one $H$. capsulatum isolate with different mating types during their period of hospitalization and treatment. The study was approved by the Research
Ethics Committee at the Instituto Nacional de Infectologia Evandro Chagas/FIOCRUZ (No 19342513.2.0000.5262), Rio de Janeiro State, Brazil.

\section{Fungal isolation and phenotypic characterization}

Fungal isolates (buffy coat from whole blood and bone marrow aspirate) from patients were cultured on Potato Dextrose Agar (Difco, Detroit, MI, USA) at $25^{\circ} \mathrm{C}$ during 21 days. The macromorfology of filamentous fungal cultures were visually examined and recorded. Colonies were described according to pigmentation (albino and scale beige - light beige, dark beige, and beige) and texture (cottony or powdery). Their micromorphologies were observed in 10 different fields by optical microscopy at a $40 \mathrm{X}$ magnification of $\mathrm{H}$. capsulatum colonies, stained with Lactophenol Cotton Blue (Fluka Analyted, France). Dimorphism was demonstrated by conversion to the yeastlike form on ML- Gema agar medium ${ }^{15}$, for 7 to 14 days at $37{ }^{\circ} \mathrm{C}$.

\section{Mating type determination}

Yeast cells were submitted to limiting dilution and a single colony was used for DNA extraction as previously reported ${ }^{16}$. The MATl locus of $H$. capsulatum isolates was identified by polymerase chain reaction (PCR) using specific pair of primers for MAT1-1 and MAT1-2 idiomorphs based in a previous protocol, with minor modifications ${ }^{17}$. Briefly, PCR was performed in a $25 \mu \mathrm{L}$ reaction mixture, containing $200 \mu \mathrm{M}$ of each deoxynucleoside triphosphate (dNTP) (Applied Biosystems Inc., Foster City, CA, USA), $1.5 \mathrm{mM} \mathrm{MgCl}, 50 \mathrm{ng} / \mu \mathrm{L}$ of each primer, 1.5 U Taq DNA polymerase (New England BioLabs Inc., MA, USA), $1 \mathrm{X} \mathrm{Taq}$ commercial buffer and $75 \mathrm{ng}(25 \mathrm{ng} / \mu \mathrm{L})$ of each DNA template. G-217B from USA (MAT1-1) and G-186AR from Panama (MATI-2) are references strains and were used as controls.

PCR assays were performed in a Thermal iCycler (BioRad Laboratories Inc., Hercules, CA, USA) programmed as follows: (a) 3 min at $95^{\circ} \mathrm{C}$; (b) 35 cycles, consisting of $30 \mathrm{~s}$ at $95^{\circ} \mathrm{C}, 30 \mathrm{~s}$ at $58{ }^{\circ} \mathrm{C}$, and $1 \mathrm{~min}$ and $30 \mathrm{~s}$ at $72{ }^{\circ} \mathrm{C}$; and (c) $10 \mathrm{~min}$ at $72^{\circ} \mathrm{C}$. Amplicons were visualized on $1.5 \%$ agarose gel electrophoresis. The 100-bp DNA ladder was used as a molecular marker. Amplicons were sequenced at the High-Throughput Genomics Center (University of Washington, Seattle, WA, USA). The obtained sequences were deposited in GenBank database (http://www.ncbi. nlm.nih.gov). They were edited and aligned for BLASTn analysis ${ }^{18}$, using as reference the sequence of the strains G-217B from USA (MAT1-1, GenBank accession 
$\mathrm{N}^{\circ}$ EF433757) and G-186AR from Panama (MAT1-2, GenBank accession N ${ }^{\circ}$ EF433756).

\section{Phylogenetic relationship among the studied isolates}

The genetic reconstruction analysis was performed by MLST using PCR amplification of partial DNA sequences from four nuclear genes (arf, H-anti, olel, and tubl) according to the protocol described by Kasuga $e t$ al. ${ }^{11}$ with some modifications. PCR was performed in $25 \mu \mathrm{L}$ of reaction mixture, containing $200 \mu \mathrm{M}$ of each deoxynucleoside triphosphate (dNTP) (Applied Biosystems Inc., Foster City, CA, USA), $2.0 \mathrm{mM} \mathrm{MgCl}_{2}, 50 \mathrm{ng} / \mu \mathrm{L}$ of each primer, $1.0 \mathrm{U} \mathrm{Taq}$ DNA polymerase (New England BioLabs Inc., MA, USA), $1 \mathrm{X} \mathrm{Taq}$ commercial buffer, and $20 \mathrm{ng}(10 \mathrm{ng} / \mu \mathrm{L})$ of each DNA template. The G-217B from USA reference strains was used as a control. PCR assays were performed in a Thermal iCycler (Bio-Rad Laboratories Inc., Hercules, CA, USA) programmed as follows: (a) $3 \mathrm{~min}$ at $95^{\circ} \mathrm{C}$; (b) 32 cycles, consisting of $15 \mathrm{sec}$ at $94{ }^{\circ} \mathrm{C}, 30 \mathrm{sec}$ at $65^{\circ} \mathrm{C}$ in the first cycle, which was subsequently reduced by $0.7^{\circ} \mathrm{C} /$ cycle for the next 12 cycles, and $1 \mathrm{~min}$ at $72{ }^{\circ} \mathrm{C}$. In the remaining 20 cycles, the annealing temperature was kept at $56^{\circ} \mathrm{C}$; (c) a final extension cycle of 5 min at $72{ }^{\circ} \mathrm{C}$ - touchdown $\mathrm{PCR}^{19}$.
Generated amplicons were also sequenced at the HighThroughput Genomics Center (University of Washington) and the sequences were deposited in the GenBank database (http://www.ncbi.nlm.nih.gov). The resulting sequences were analyzed by BLASTn ${ }^{17}$, using the sequences of the G-217B strain as reference (GenBank accession $\mathrm{N}^{\circ}$ L25117.1, U20346.1, X85962.1, and M28358.1).

To identify the relationships of the five studied isolates with other $H$. capsulatum isolates previously characterized by the four aforementioned nuclear genes, a combined matrix using partial sequences of these genes was generated and edited manually by MESQUITE ver. $2.75^{20}$. This matrix was constructed with 260 sequences, considering four genes per isolate, out of 65 analyzed $H$. capsulatum isolates: 57 isolates from TreeBASE (http://treebase.org, study ID S1063) reported by Kasuga et al. ${ }^{11}$; three from GenBank with their respective accession numbers for arf, H-anti, ole1, and tub1 genes (EH-383I isolate- AF495619, AF495620, AF495621, and AF495622; and EH-375 isolateAF495607, AF495608, AF495609, and AF495610; and the G-217B strain, see the aforementioned GenBank accession numbers); and the five $H$. capsulatum clinical isolates reported in this study. Details of the $65 \mathrm{H}$. capsulatum isolates are in Tables 1 and 2.

Table 1 - Major data of $H$. capsulatum strains/isolates whose sequences were acquired from databases of the MLST analysis of the present study. (continues on the next page)

\begin{tabular}{|c|c|c|c|c|}
\hline Strain/isolate & Phylogenetic clade & Source & Origin & Year of isolation \\
\hline Downs $(\mathrm{H} 9)^{\star}$ & NAm 1 & Human & USA & 1968 \\
\hline $\mathrm{H} 79^{*}$ & NAm 1 & Skunk & USA & 1967 or before \\
\hline $\mathrm{H} 126^{*}$ & NAm 1 & Human/HIV+ & USA & 1987 \\
\hline $\mathrm{H} 127^{*}$ & NAm 1 & Human/HIV+ & USA & 1987 \\
\hline G-217B (H8)† & NAm 2 & Human & USA & 1973 or before \\
\hline $\mathrm{H} 11^{*}$ & NAm 2 & Human & USA & 1993 or before \\
\hline $\mathrm{H} 97^{*}$ & NAm 2 & Human & USA & 1995 or before \\
\hline H139* & NAm 2 & Soil & USA & 1975 \\
\hline $\mathrm{H} 179^{*}$ & NAm 2 & Human & USA & Not known \\
\hline $\mathrm{H} 146^{*}$ & LAm A & Human & Brazil & 1979 \\
\hline $\mathrm{H} 149^{*}$ & $\operatorname{LAm} A$ & Human/HIV+ & Brazil & 1996 \\
\hline $\mathrm{H} 150^{*}$ & LAm A & Human & Brazil & 1996 \\
\hline $\mathrm{H} 151^{*}$ & $\operatorname{LAm} A$ & Human/HIV+ & Brazil & 1997 \\
\hline $\mathrm{H} 152^{*}$ & LAm A & Human/HIV+ & Brazil & 1997 \\
\hline $\mathrm{H} 155^{*}$ & LAm A & Human/HIV+ & Brazil & 1998 \\
\hline $\mathrm{H} 67^{*}$ & LAm A & Human & Colombia & 1993 \\
\hline $\mathrm{H} 61^{*}$ & LAm A & Human & Colombia & 1993 \\
\hline $\mathrm{H} 62^{*}$ & LAm A & Human & Colombia & 1993 \\
\hline $\mathrm{H} 63^{*}$ & LAm A & Human & Colombia & 1989 \\
\hline
\end{tabular}


Table 1 - Major data of $H$. capsulatum strains/isolates whose sequences were acquired from databases of the MLST analysis of the present study. (cont.)

\begin{tabular}{|c|c|c|c|c|}
\hline Strain/isolate & Phylogenetic clade & Source & Origin & Year of isolation \\
\hline $\mathrm{EH}-46^{*}$ & LAm A & Human & Mexico & 1979 \\
\hline $\mathrm{EH}-53^{*}$ & $\operatorname{LAm} \mathrm{A}$ & Human & Mexico & 1977 \\
\hline $\mathrm{EH}-317^{*}$ & LAm A & Human/HIV+ & Mexico & 1992 \\
\hline L-100-91 (EH-333)* & LAm A & Black bird excreta & Guatemala & 1991 \\
\hline EH-383I† & LAm A & Bat & Mexico & 1997 \\
\hline CEPA 2 (EH-362)* & LAm A & Black bird excreta & Guatemala & 1996 \\
\hline CEPA 3 (EH-363)* & LAm A & Human & Guatemala & 1996 \\
\hline H.1.04.91 (EH-304)* & LAm A & Human & Guatemala & 1991 \\
\hline H.1.11.94 (EH-332)* & LAm A & Human & Guatemala & 1994 \\
\hline EH-375† & LAm A & Bat & Mexico & 1997 \\
\hline $\mathrm{H} 162$ * & LAm B & Human/HIV+ & Argentina & 1998-1999 \\
\hline $\mathrm{H}_{163^{*}}$ & LAm B & Human/HIV+ & Argentina & 1998-1999 \\
\hline $\mathrm{H} 164^{*}$ & LAm B & Human/HIV+ & Argentina & 1998-1999 \\
\hline $\mathrm{H} 165^{*}$ & LAm B & Human/HIV+ & Argentina & 1998-1999 \\
\hline $\mathrm{H} 166^{*}$ & LAm B & Human/HIV+ & Argentina & 1998-1999 \\
\hline $\mathrm{H} 148^{*}$ & Eurasia & Horse & Not known & 1935 \\
\hline $\mathrm{H} 178^{*}$ & Eurasia & Human & China & Not known \\
\hline $\mathrm{H} 192^{*}$ & Eurasia & Human & India & Not known \\
\hline $\mathrm{H} 194^{*}$ & Eurasia & Horse & Egypt & Not known \\
\hline $\mathrm{H} 206^{*}$ & Eurasia & Human & Thailand & 1994 \\
\hline $\mathrm{H} 87^{*}$ & Africa & Human & Guinea-Liberian border & 1970 \\
\hline $\mathrm{H} 137^{*}$ & Africa & Human & Zaire & 1962 \\
\hline $\mathrm{H} 147^{*}$ & Africa & Human & Senegal & 1957 \\
\hline $\mathrm{H} 187^{*}$ & Africa & Bat guano & Nigeria & 1991 \\
\hline $\mathrm{H} 189^{*}$ & Africa & Not known & Not known & Not known \\
\hline $\mathrm{H} 157^{*}$ & Australia & Human & Australia & $1970 s$ \\
\hline $\mathrm{H} 158^{*}$ & Australia & Soil/bat guano & Australia & 1984 \\
\hline $\mathrm{H} 159^{*}$ & Australia & Human & Australia & 1984 \\
\hline $\mathrm{H} 160^{*}$ & Australia & Human/HIV+ & Australia & 1988 \\
\hline $\mathrm{H} 161^{*}$ & Australia & Human/HIV+ & Australia & 1990 \\
\hline $\mathrm{H} 144^{*}$ & Netherlands & Human & Netherlands & 1965 \\
\hline $\mathrm{H} 176^{*}$ & Netherlands & Human & Netherlands & 1969 \\
\hline $\mathrm{H} 66^{*}$ & Lineage & Human & Colombia & 1986 \\
\hline H69* & Lineage & Human & Colombia & 1991 \\
\hline $\mathrm{H} 153^{\star}$ & Linage & Human & Brazil & 1997 \\
\hline G-186B (H83)* & Lineage & Human & Panama & 1967 or before \\
\hline $\mathrm{G}-186 \mathrm{~A}(\mathrm{H} 82)^{*}$ & Lineage & Human & Panama & 1967 or before \\
\hline G-184B $(\mathrm{H} 81)^{*}$ & Lineage & Human & Panama & 1967 or before \\
\hline $\mathrm{H} 140^{*}$ & Lineage & Owl monkey & USA/Peru & 1997 \\
\hline $\mathrm{H} 185^{\star}$ & Lineage & Owl monkey & USA/Peru & 1999 \\
\hline $\mathrm{EH}-315^{*}$ & Lineage & Bat & Mexico & 1994 \\
\hline
\end{tabular}

The sequences of all $H$. capsulatum strains/isolates in this table were obtained from *TreeBase and †GenBank. Numbers in parenthesis are acronyms. 
Table 2 - Characteristics of $H$. capsulatum isolates associated with mixed infections.

\begin{tabular}{|c|c|c|c|c|c|}
\hline \multirow{2}{*}{$\begin{array}{l}\text { Characteristics of } \\
\text { fungal isolates }\end{array}$} & \multicolumn{3}{|c|}{ Patient 1} & \multicolumn{2}{|c|}{ Patient 2} \\
\hline & CE0311 & CE0411 & CE0511 & CE2813 & CE2513 \\
\hline Source & Buffy coat & Bone marrow & Buffy coat & Buffy coat & Buffy coat \\
\hline Day of hospitalization & $1^{\circ}$ & $1^{\circ}$ & $2^{\circ}$ & $3^{\circ}$ & $12^{\circ}$ \\
\hline Pigmentation of colonies & Albino & Light-beige & Beige & Dark-beige & Light-beige \\
\hline Texture of colonies & Cottony & Cottony & Cottony & Powdery & Powdery \\
\hline Mating type & MAT1-1 & MAT1-1 & MAT1-2 & MAT1-1 & MAT1-2 \\
\hline
\end{tabular}

The generated combined matrix containing 1539-nt was analyzed through two methods: a) Maximum likelihood (ML) in RaxMLGUI ver. $1.31^{21}$ through the General Time Reversible substitution model gamma distribution; and b) Bayesian inference (BI) by MrBayes ver. 3.2 22 with a final run using four chains for a total of 100,000,000 generations and sampling trees every 10,000 generations. The substitution models considered in BI for each partition were K80 (H-anti), K80+G with four categories (arf and tub1), and $\mathrm{K} 80+\mathrm{I}$ (ole1). The substitution models for ML and BI methods were selected according to Akaike Information Criterion and Bayesian information criterion tests, implemented in Jmodeltest ver. 2.1.4 for ML and $\mathrm{BI}^{23}$, respectively.

Bootstrap values (bt) for ML analysis were based on 1000 heuristic search replicates, using Tree-BisectionReconnection. For the BI analysis, the maximum clade credibility tree was selected with a posterior probability (pp) limit of 0.95, using TreeAnotator ver. 1.8.2, implemented in BEAST - Bayesian Evolutionary Analysis Sampling Trees ${ }^{24,25}$. An unrooted tree was constructed using the combined matrix.

\section{RESULTS}

During the study period, 40 AIDS-patients were hospitalized in the Sao Jose Hospital with histoplasmosis diagnosis confirmed by culture in different biologic samples. For this study, six patientswere recruited and 13 biologic samples of these six patients, which were available for mating type - PCR. Four patients presented the same mating type, two patients with MAT 1-1 and two patients with MAT 1-2. However, for this report we selected only the two patients presenting with $H$. capsulatum isolates with different mating types.

\section{Patient 1}

A 22-year-old male AIDS-patient was admitted in an infectious diseases hospital with fever, diarrhea, asthenia, and a weight loss of $6 \mathrm{~kg}$. He was a craftsman and lived in an urban area of Baturite, Ceara State, Brazil. Physical examination revealed cervical adenomegaly and hepatosplenomegaly. Pulmonary and cardiac auscultation as well as vital signs were normal. He used antiretroviral drugs irregularly (estavudine, lamivudine, and efavirenz). Laboratory evaluations revealed hemoglobin level of $9.3 \mathrm{~g} / \mathrm{dL}$, white blood cells count $1,200 / \mathrm{mm}^{3}$ (neutrophils $=$ $80 \%$; lymphocytes $=10.8 \%$; monocytes $=4.2 \%$; eosinophils $=5 \%$ ), and platelets count $65,000 / \mathrm{mm}^{3}$. Renal function was normal. The level of lactate dehydrogenase (LDH) was high (2,086 U/L). Aspartate aminotransferase (AST) level was $274 \mathrm{U} / \mathrm{L}$, alanine aminotransferase (ALT) level was $67 \mathrm{U} / \mathrm{L}$ and alkaline phosphate (AP) was 184 U/L. The patient had CD4+ lymphocytes count of 273 cells $/ \mathrm{mm}^{3}$ and plasma HIV-RNA of 127,240 copies/mL. $H$. capsulatum yeast-like was visualized by Giemsa staining of buffy coat smear. Therapy with amphotericin B (1 mg/kg per day) was administered and the patient was discharged after 35 days of hospitalization. In the clinical follow-up, the antifungal therapy was maintained with amphotericin B once a week for 6 month.

\section{Patient 2}

A 52-year-old male AIDS-patient was admitted in an infectious diseases hospital with fever, abdominal pain, cough, dyspnea, hematochezia, and weight loss. He had a history of an oral mucosa lesion for the last 2 months. He was engaged in farming activities and lived in a rural area of Maracanau, Ceara State, Brazil. His vital signs were as follow: temperature $37.2^{\circ} \mathrm{C}$; pulse rate $106 / \mathrm{min}$, respiratory frequency $30 / \mathrm{min}$, and blood pressure $70 / 30 \mathrm{~mm} \mathrm{Hg}$. A physical examination revealed pallor, oral ulcer with partial destruction of uvula, and oral candidiasis. Cardiac auscultation revealed systolic murmur, and chest auscultation detected crackles in the base of the left lung. The abdominal examination revealed hepatosplenomegaly. He used antiretroviral drugs irregularly (zydovudine, lamivudine, atazanavir, and ritonavir). Laboratory 
evaluations revealed hemoglobin level of $4.3 \mathrm{~g} / \mathrm{dL}$, white blood cells count $3,860 / \mathrm{mm}^{3}(1 \%$; neutrophils $=64 \%$; lymphocytes $=24 \%$; monocytes $=8 \%$; eosinophils $=2 \%$; basophiles $=1 \%$ ), and platelets count $34,000 / \mathrm{mm}^{3}$. Renal function was normal. A high level of LDH was observed $(1,402 \mathrm{U} / \mathrm{L})$. Hepatic function was altered $(\mathrm{AST}=97 \mathrm{U} / \mathrm{L}$, $\mathrm{ALT}=32 \mathrm{U} / \mathrm{L}, \mathrm{AP}=908 \mathrm{U} / \mathrm{L}, \gamma \mathrm{GT}=197 \mathrm{U} / \mathrm{L})$. The patient had CD4+ lymphocytes count of 80 cells $/ \mathrm{mm}^{3}$. A chest $\mathrm{X}$-ray showed diffuse reticulonodular pulmonary infiltrate. Empiric therapy with amphotericin B ( $1 \mathrm{mg} / \mathrm{kg}$ per day) was started on day 1 . However, the patient presented respiratory and renal failure. He died after 18 days of hospitalization.

\section{Fungal cultures and morphological identification}

H. capsulatum were isolated from patients' clinical samples during their hospitalization and treatment. Three $H$. capsulatum isolates were obtained from patient 1 , one from bone marrow (day 1 - CE0411) and two from buffy coat (day 1-CE0311; day 2-CE0511). Two H. capsulatum isolates were recovered from buffy coat of patient 2 on day 3 (CE2813) and day 12 (CE2513) of hospitalization. H. capsulatum mycelial cultures of patient 1 presented a cottony texture macromorphology, whereas mycelial cultures of patient 2 were powdery. Different pigmentations were observed in the fungal cultures of both patients. These morphological characteristics are in Table 2. In regard to micromorphology, all fungal isolates had hyaline, septated and branched thin hyphae, microconidia and tuberculate macroconidia. Dimorphic conversion occurred in all $H$. capsulatum isolates, with typical budding yeast cells. Figure 1 shows a representative micromorphology of the five fungal isolates recovered in this study.

\section{Mating types of $H$. capsulatum isolates recovered from the AIDS-patients}

The MAT1-1 idiomorph was identified in H. capsulatum isolates CE0311 and CE0411 (patient 1) as well as in CE2813 (patient 2) isolates; whereas the MAT1-2 idiomorph was found in CE0511 (patient 1) and CE2513 (patient 2) isolates. The sequences of the MAT1 locus for these five fungal isolates are available in the GenBank (accession numbers in Table 3) and they were compatible with $A$. capsulatus through BLASTn analysis $^{18}$. The CE0311 and CE0411 isolates showed 99\% similarity and CE2813 isolate

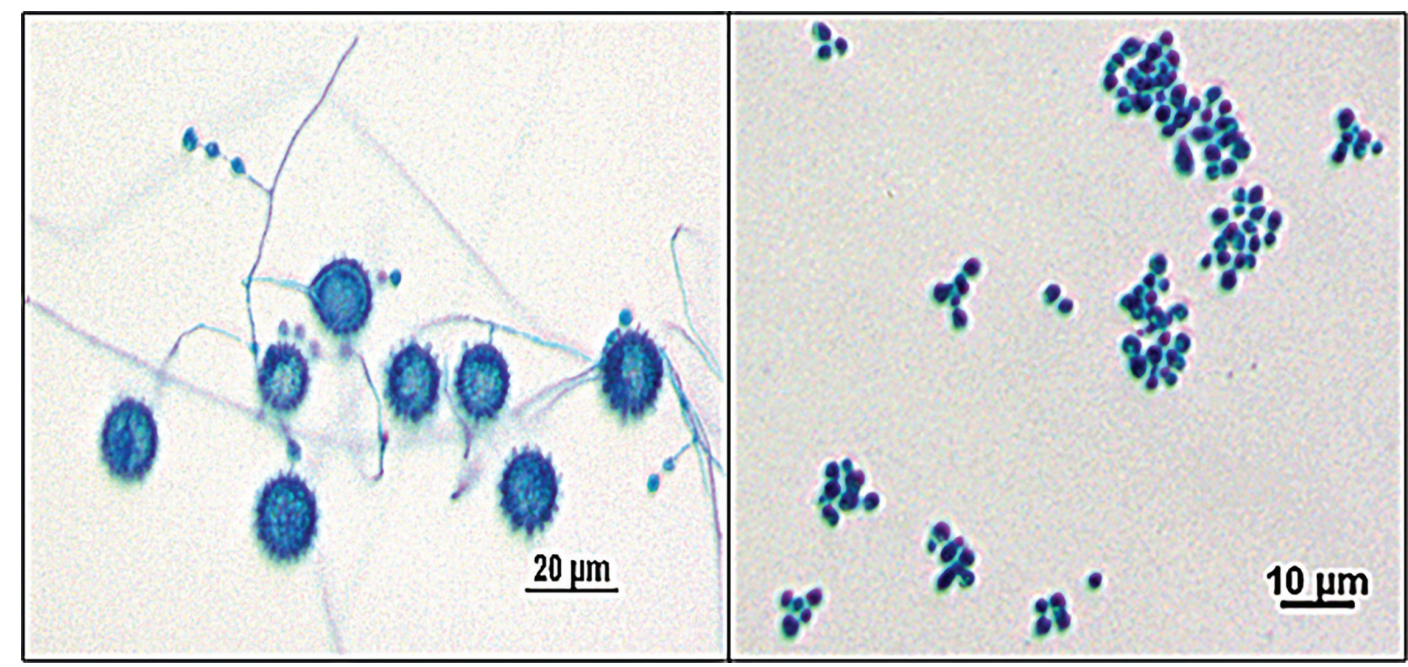

Figure 1 - Representative micromorphology of H. capsulatum mycelium and yeast phases of CE0411 isolate from an AIDS-patient. Both fungal phases were stained by Lactophenol Cotton Blue. Magnification of $40 \mathrm{X}$.

Table 3 - GenBank accession numbers of the sequences from each gene used to characterize the five $H$. capsulatum isolates in the present study.

\begin{tabular}{lccccc}
\hline Fungal isolate & MAT1 & Arf & H-anti & ole1 & tub1 \\
\hline CE 0311 & KX058315 & KX058302 & KX058322 & KX058307 & KX058312 \\
CE0411 & KX058314 & KX058301 & KX058321 & KX058306 & KX058311 \\
CE0511 & KX058317 & KX058300 & KX058320 & KX058305 & KX058310 \\
CE2813 & KX058313 & KX058298 & KX058318 & KX058303 & KX058309 \\
CE2513 & KX058316 & KX058299 & KX058319 & KX058304 & KX058308 \\
\hline
\end{tabular}


showed $100 \%$ similarity with the sequence of the G-217B reference strain (MAT1-1), whereas CE0511 and CE2513 isolates showed $97 \%$ similarity with the sequence of the G-186AR reference strain (MAT1-2).

\section{Phylogenetic analyses of the $H$. capsulatum isolates}

These partial sequences obtained from the five $H$. capsulatum isolates were deposited in GenBank (accession numbers in Table 3). The phylogenetic trees for the four genes analyzed by either ML or BI methods presented similar topologies. A BI phylogenetic tree was constructed to support both ML and BI data, where bt and pp values were represented in each tree node (Figure 2).
The five $H$. capsulatum isolates from the AIDS-associated histoplasmosis patients were grouped in the LAm A clade together with other LAm A isolates included in the present study (Table 1, Figure 2). The CE0311 and CE0411 isolates from patient 1 share the same branch with the $\mathrm{H} 146$ isolate from Brazil, supported by bt $=74 \%(\mathrm{ML})$ and $\mathrm{pp}=1.0(\mathrm{BI})$ values. On the other hand, CE0511 (patient 1), CE2513 and CE2813 (patient 2) isolates were clustered together and share a branch with Brazilian H151 and H149 isolates (bt $=56 \%$ in $\mathrm{ML}, \mathrm{pp}=1.0$ in $\mathrm{BI}$ ) (Figure 2). In regard to the sequences of other isolates used to develop the MLST analyses, Figure 2 shows that they clustered according to Kasuga et al..$^{11}$ criterion, representing the different clades reported in Table 1.

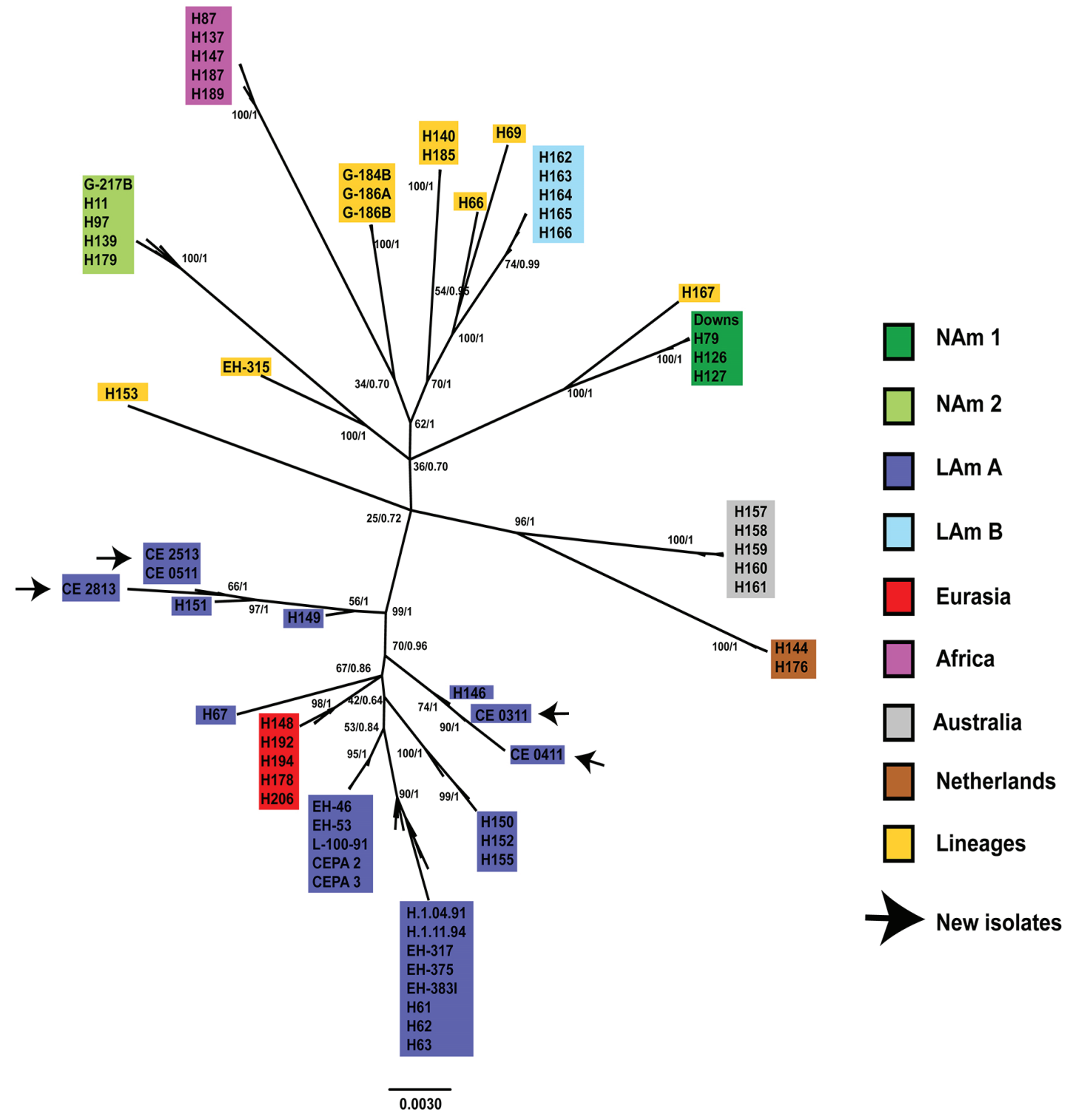

Figure 2 - Unrooted phylogenetic tree of $H$. capsulatum isolates. The tree was constructed with a concatenated matrix of 1539-nt using four gene fragments (arf, $\mathrm{H}$-anti, ole1, and tub1). It was generated by $\mathrm{BI}$ and is representative of both $\mathrm{ML}$ and $\mathrm{BI}$ analyses. The values of $\mathrm{bt} / \mathrm{pp}$ are indicated on their corresponding tree nodes. 


\section{DISCUSSION}

This study reports for the first time in theliterature, two cases of mixed infection caused by H. capsulatum isolates with different mating types in AIDS-patients, highlighting the genetic diversity among the five fungal isolates recovered from clinical samples. The $H$. capsulatum isolates associated with mixed infections were from the Ceara State, which is an endemic area of histoplasmosis in Northeast Brazil. This mycosis usually occurs in AIDS-patients, and a high mortality rate has been recorded (30-40\%) among them ${ }^{2,26}$.

Mixed infections caused by microorganisms with different genetic profiles have been described mainly with pathogenic bacteria ${ }^{27,28}$. Fungal mixed infection with different mating types of the same species was described in individuals colonized or infected by Aspergillus fumigatus ${ }^{10}$. However, the clinical consequences of this event are still unknown. It is suggested that the mechanisms driving mixed infections include microevolution of pre-existing clones, simultaneous coinfection by recently acquired strains, and superinfection by a new strain different from preexisting clones ${ }^{29,30}$. Here, mixed infections caused by different isolates were supported by the finding of different $H$. capsulatum mating type's idiomorphs in the same patient, at different time points of the histoplasmosis treatment.

Some studies have also shown that the mating system of Cryptococcus neoformans and A. fumigatus is associated with virulence of these pathogens as well as with the severity of infections ${ }^{8,9,31}$. MATI-1 has been associated with invasive aspergillosis ${ }^{32}$ and in $C$. neoformans infections, the $\alpha$-mating type has been described as more virulent than the a-mating type ${ }^{8,31}$. However, more recently, experimental studies revealed that there is not association between mating type and virulence of $C$. neoformans and A. fumigatus ${ }^{33,34}$.

The sexual reproduction by meiosis between strains with different mating types can generate genetic variability, which is very important for lineage survival. In addition, this process can lead to the formation of hypervirulent strains, as well as strains with the ability to evade the host's immune response and with increased resistance to antifungal drugs ${ }^{7,30}$.

Few studies have investigated the mating type of $H$. capsulatum isolates and its impact on the virulence of the pathogen ${ }^{5,35}$. Conventional methods, such as in vitro cross mating between isolates of $H$. capsulatum, identified a predominance of MAT1-2 in clinical isolates from USA patients with acute pulmonary histoplasmosis ${ }^{35}$. In 2007, a molecular study identified MATI-1 in strains from USA isolated from a patient with unusual histoplasmosis (G-217B) and UH1 isolate obtained from a transplanted patient with disseminated histoplasmosis. MAT1-2 was related to the strain G-186AR from Panama and the strains VA1 and T-3-1 from USA ${ }^{6}$.

More recently, several environmental and clinical H. capsulatum isolates from Mexico and Brazil were characterized concerning their MAT1 locus by $\mathrm{PCR}^{17}$. Six out of 28 studied fungal isolates were obtained from patients with disseminated histoplasmosis, where three isolates came from HIV-patients (two from Brazil and one from Mexico). The MAT1-1 was found in all (11 environmental and three clinical) isolates studied from Brazil, whereas the MAT1-2 was predominantly identified in most of the Mexican $H$. capsulatum isolates, including two clinical isolates. Interestingly, MATl- 1 idiomorph was also identified in four isolates from Mexico, where one of these was isolated from an HIV-patient ${ }^{17}$. As new data, it was reported here two MAT1-2 H. capsulatum isolates from Brazil. Undoubtedly, more studies are necessary to characterize the distribution and the impact of mating types in H. capsulatum isolates from different regions of the Americas.

Among the morphological characteristics recorded for the studied $H$. capsulatum isolates, pigmentation was the sole divergent factor. It is well known that pigmentation of fungal isolates depends on the culture medium, age of strainand melanin production. Even though the melanization of $H$. capsulatum protects the fungus against antifungal drugs such as amphotericin $\mathrm{B}^{36}$, experimental studies did not find any difference in virulence between albino (nonmelanized) and brown (melanized) H. capsulatum strains ${ }^{37}$.

All $H$. capsulatum isolates of this study were identified within the former LAm A clade by MLST analyses, which also revealed genetic diversities among the fungal isolates of each patient. According to the new phylogenetic clusters proposed by Teixeira et al. ${ }^{14}$, the isolates CE0311 and CE0411 would be classified within the BR4 clade together with H146; and CE0511, CE2513, and CE2813 within the BR2 clade together H151. Thus, isolates from patient 1, CE0311 and CE0411, grouped in a different cluster from that of isolate CE0511; whereas isolate CE2513 from patient 2 showed a high genetic similarity with the CE0511 isolate from patient 1 , supported by bt and pp values of ML and BI trees, respectively (Figure 2). Based on these genetic findings and considering the differences in the MATl locus described in the H. capsulatum isolates of the same patient, it is possible to assume that these fungal mixed infections could be explained by simultaneous coinfection with a new isolate that diverged and coexists in the same area, or by superinfection with a latent Histoplasma infection. Previous phylogenetic studies with different molecular markers have demonstrated that there is a high genetic diversity among $H$. capsulatum isolates from diverse regions, as well as in the same region ${ }^{11-14,38-40}$. Therefore, coinfection and 
superinfection are events that can occur in mixed infections and cannot be discarded in H. capsulatum infections. In spite of all this, more studies aiming at evaluating the consequences of mixed infections with $H$. capsulatum harboring different genetic and morphologic characteristics are necessary to better understand the pathogenesis of histoplasmosis.

\section{CONCLUSIONS}

This research indicates that mixed infection caused by H. capsulatum isolates with different mating types can occur due to different mechanisms as microevolution, coinfection or superinfection. More studies are necessary to evaluate the results this coinfection in the virulence of pathogen and in the pathogenesis of histoplasmosis.

\section{ACKNOWLEDGMENTS}

LSD thanks the Programa de Pós-Graduação Stricto Sensu em Pesquisa Clínica em Doenças Infecciosas do Instituto Nacional de Infectologia Evandro Chagas, FIOCRUZ and the scholarship No 99999.002336/2014-06 provided by the Programa Institucional de Bolsas de Doutorado Sanduiche no Exterior from the Coordenação de Aperfeiçoamento de Pessoal de Nivel Superior (CAPES), Brazil. The authors thank Ingrid Mascher and Rodrigo de Almeida Paes for their editorial assistance.

\section{FINANCIAL SUPPORT}

RMZ-O was supported in part by CNPq [304976/20130] and FAPERJ [E-26/103.157/2011]. This research was also partially supported by a grant provided by Programa de Apoyo a Proyectos de Investigación e Innovación Tecnológica-Dirección General de Asuntos del Personal Académico from UNAM [PAPIIT-DGAPA/UNAM, Reference $\mathrm{N}^{\circ}$ IN213515].

\section{CONFLICT OF INTERESTS}

The authors declare that there is no conflict of interests among them and with any financial organization regarding the material discussed in the present manuscript.

\section{AUTHORS' CONTRIBUTIONS}

LSD, TVG, JAR, GRA, MAA, JRLM carried out the laboratory work of the study; LSD, TVG, MMM, MLT, RMZO evaluated and interpreted data; LSD, TMJSL, MLT, RMZO drafted the manuscript; All authors participated in the design of the study and revised manuscript. All authors have contributed intellectually during the writing process and have read and approved the final manuscript.

\section{REFERENCES}

1. Taylor ML, Reyes-Montes MR, Chávez-Tapia CB, CurielQuesada E, Duarte-Escalante E, Rodríguez-Arellanes G, et al. Ecology and molecular epidemiology findings of Histoplasma capsulatum, in Mexico. In: Mojan RM, Benedik M, editors. Research advances in microbiology. Kerala : Global Research Network; 2000. p.29-35.

2. Dasmasceno LS, Novaes Jr AR, Alencar CH, Lima DT, Sidrim JJ, Gonçalves MV, et al. Disseminated histoplasmosis and AIDS: relapse and late mortality in endemic area in North-Eastern Brazil. Mycoses. 2013;56:520-6.

3. Kwon-Chung KJ. Sexual stage of Histoplasma capsulatum. Science. 1972;175:326.

4. Kwon-Chung KJ. Emmonsiella capsulata: perfect state of Histoplasma capsulatum. Science. 1972;177:368-9.

5. Kwon-Chung KJ, Weeks RJ, Larsh HW. Studies on Emmonsiella capsulata (Histoplasma capsulatum). II. Distribution of the two mating types in 13 endemic states of the United States. Am J Epidemiol. 1974;99:44-9.

6. Bubnick M, Smulian AG. The MAT1 locus of Histoplasma capsulatum is responsive in a mating type-specific manner. Eukaryot Cell. 2007;6:616-21.

7. Muniz MM, Sousa CN, Oliveira MM, Pizzini CV, Almeida MA, Rodríguez-Arellanes G, et al. Sexual variability in Histoplasma capsulatum and its possible distribution: what is going on? Rev Iberoam Micol. 2014;31:7-10.

8. Kwon-Chung KJ, Edman JC, Wickes BL. Genetic association of mating types and virulence in Cryptococcus neoformans. Infect Immun. 1992;60:602-5.

9. Cheema MS, Christians JK. Virulence in an insect model differs between mating types in Aspergillus fumigates. Med Mycol. 2011;49:202-7.

10. Alvarez-Perez S, Garcia ME, Bouza E, Pelaez T, Blanco JL. Characterization of multiple isolates of Aspergillus fumigatus from patients: genotype, mating type and invasiveness. Med Mycol. 2009;47:601-8.

11. Kasuga T, White TJ, Koenig G, McEwen J, Restrepo A, Castañeda E, et al. Phylogeography of the fungal pathogen Histoplasma capsulatum. Mol Ecol. 2003;12:3383-401.

12. Vite-Garín T, Estrada-Bárcenas DA, Cifuentes J, Taylor ML. The importance of molecular analyses for understanding the genetic diversity of Histoplasma capsulatum: an overview. Rev Iberoam Micol. 2014;31:11-5.

13. Damasceno LS, Leitão TM, Taylor ML, Muniz MM, ZancopéOliveira RM. The use of genetic markers in the molecular epidemiology of histoplasmosis: a systematic review. Eur J Clin Microbiol Infect Dis. 2016;35:19-27. 
14. Teixeira MM, Patané JS, Taylor ML, Goméz BL, Theodoro RC, de Hoog S, et al. Worldwide phylogenetic distributions and population dynamics of the genus Histoplasma. PLoS Negl Trop Dis. 2016;10:e004732.

15. Fressatti R, Dias-Siqueira L, Svidzinski TI, Herrero F, Kemmelmeier C. A medium for inducing conversion of Histoplasma capsulatum var. capsulatum into its yeast-like form. Mem Inst Oswaldo Cruz. 1992;87:53-8.

16. Muniz MM, Tavares PM, Meyer W, Nosanchuk JD, ZancopéOliveira RM. Comparison of different DNA-based methods for molecular typing of Histoplasma capsulatum. Appl Environ Microbiol. 2010;76:4438-47.

17. Rodríguez-Arellanes G, Sousa CN, Medeiros-Muniz M, Ramírez JA, Pizzini CV, Almeida MA, et al. Frequency and genetic diversity of the MAT1 locus of Histoplasma capsulatum isolates in Mexico and Brazil. Eukaryot Cell. 2013;12:1033-8.

18. Altschul SF, Gish W, Miller W, Myers EW, Lipman DJ. Basic local alignment search tool. J Mol Biol. 1990;215:403-10.

19. Don RH, Cox PT, Wainwright BJ, Baker K, Mattick JS. 'Touchdown' PCR to circumvent spurious priming during gene amplification. Nucleic Acids Res. 1991;19:4008.

20. Maddison DR, Maddison WP. Mesquite: a modular system for evolutionary analysis. [cited 2019 Jan 14]. Available from: http://mesquiteproject.org

21. Stamatakis A. RAxML version 8: a tool for phylogenetic analysis and post-analysis of large phylogenies. Bioinformatics. 2014;30:1312-3.

22. Ronquist F, Teslenko M, van der Mark P, Ayres DL, Darling A, Hohna S, et al. MrBayes 3.2: efficient Bayesian phylogenetic inference and model selection across a large model space. Syst Biol. 2012;61:539-42.

23. Darriba D, Taboada GL, Doallo R, Posada D. jModelTest 2: more models, new heuristics and parallel computing. Nat Methods. 2012;9:772.

24. Drummond AJ, Suchard MA, Xie D, Rambaut A. Bayesian phylogenetics with BEAUti and the BEAST 1.7. Mol Biol Evol. 2012;29:1969-73.

25. Heled J, Drummond AJ. Bayesian inference of species trees from multilocus data. Mol Biol Evol. 2010;27:570-80.

26. Brilhante RS, Fechine MA, Mesquita JR, Cordeiro RA, Rocha MF, Monteiro AJ, et al. Histoplasmosis in HIV-positive patients in Ceara, Brazil: clinical-laboratory aspects and in vitro antifungal susceptibility of Histoplasma capsulatum isolates. Trans R Soc Trop Med Hyg. 2012;106:484-8.

27. Martin IM, Ison CA. Detection of mixed infection of Neisseria gonorrhoeae. Sex Transm Infec. 2003;79:56-8.

28. García de Viedma D, Alonso Rodriguez N, Andrés S, Ruiz Serrano MJ, Bouza E. Characterization of clonal complexity in tuberculosis by mycobacterial interspersed repetitive unitvariable-number tandem repeat typing. J Clin Microbiol. 2005;43:5660-4.
29. Ene IV, Bennett RJ. The cryptic sexual strategies of human fungal pathogens. Nat Rev Microbiol. 2014;12:239-51.

30. García de Viedma D, Marín M, Ruiz Serrano MJ, Alcalá L, Bouza E. Polyclonal and compartmentalized infection by Mycobacterium tuberculosis in patients with both respiratory and extrarespiratory involvement. J Infect Dis. 2003;187:695-9.

31. Nielsen K, Marra RE, Hagen F, Boekhout T, Mitchell TG, Cox $\mathrm{GM}$, et al. Interaction between genetic background and the mating-type locus in Cryptococcus neoformans virulence potential. Genetics. 2005; 171:975-83.

32. Alvarez-Perez S, Blanco JL, Alba P, Garcia ME. Mating type and invasiveness are significantly associated in Aspergillus fumigatus. Med Mycol. 2010;48:273-7.

33. Zhai B, Zhu P, Foyle D, Upadhyay S, Idnurm A, Lin X. Congenic strains of the filamentous form of Cryptococcus neoformans for studies of fungal morphogenesis and virulence. Infect Immun. 2013;81:2626-37.

34. Losada L, Sugui JA, Eckhaus MA, Chang YC, Mounaud S, Figat A, et al. Genetic analysis using an isogenic mating pair of Aspergillus fumigatus identifies azole resistance genes and lack of mat locus's role in virulence. PLoS Pathog. 2015;11:e1004834.

35. Kwon-Chung KJ, Bartlett MS, Wheat LJ. Distribution of the two mating types among Histoplasma capsulatum isolates obtained from an urban histoplasmosis outbreak. Sabouraudia. 1984;22:155-7.

36. Gómez BL, Nosanchuk JD. Melanin and fungi. Curr Opin Infect Dis. 2003;16:91-6.

37. Campbell CC, Berliner MD. Virulence differences in mice of type $\mathrm{a}$ and $\mathrm{b}$ Histoplasma capsulatum yeasts grown in continuous light and total darkness. Infect Immun. 1973;8:677-8.

38. Muniz MM, Pizzini CV, Peralta JM, Reiss E, Zancopé-Oliveira RM. Genetic diversity of Histoplasma capsulatum strains isolated from soil, animals, and clinical specimens in Rio de Janeiro State, Brazil, by a PCR-based random amplified polymorphic DNA assay. J Clin Microbiol. 2001;39:4487-94.

39. Taylor ML, Hernández-García L, Estrada-Bárcenas D, SalaLizana R, Zancopé-Oliveira RM, García de la Cruz S, et al. Genetic diversity of Histoplasma capsulatum isolated from infected bats randomly captured in Mexico, Brazil and Argentina, using the polymorphism of $(\mathrm{GA})_{\mathrm{n}}$ microsatellite and its flanking regions. Fungal Biol. 2012;116:308-17.

40. Taylor ML, Chávez-Tapia CB, Rojas-Martínez A, de Rocio ReyesMontes M, Bobadilla del Valle M, Zuñiga G. Geographical distribution of genetic polymorphism of the pathogen Histoplasma capsulatum isolated from infected bats, captured in a central zone of Mexico. FEMS Immunol Med Microbiol. 2005;45:451-8. 